\title{
Risk Control of Manufacturing Enterprise Short-term Financial Investment Based on COSO-ERM and Industry 4.0
}

\author{
Lian $\mathrm{He}^{1}$, Xiaoxin Chen ${ }^{2}$ \\ ${ }^{1}$ Department of Business Administration, Zhuhai College of Jilin University, Zhuhai, 519041, China \\ ${ }^{2}$ Zhuhai Huazheng Consulting \& Service Limited, Zhuhai, 519000, China
}

\begin{abstract}
In this paper, firstly, the risk management and control process of related enterprises after COSO-ERM framework is introduced and the risk assessment and control methods of related investment strategies are introduced emphatically by studying the short-term financial investment business of manufacturing enterprises. Then, the risk probability method for measuring the risk size and the possibility of achieving the expected goals is introduced. Next, the differences between the risk curve and the risk probability curve are further compared. Finally, in Industry 4.0, it is concluded that the introduction of COSO-ERM framework into manufacturing enterprise risk management will not only help to grasp the implementation of enterprise strategic objectives through effective internal control, but also help to effectively assess the risks of strategic objectives and the possibility of achieving strategic objectives.
\end{abstract}

Keywords: COSO-ERM, risk management and control, risk probability, Industry 4.0

\section{Research Background}

A basic precondition of enterprise risk management is that every organization, whether for-profit, non-profit, or government agency, aims to provide value for its stakeholders. Since all organizations are faced with uncertainty, the challenge for management lies in how much uncertainty it faces while pursuing value increment. Uncertainty implies the destruction or enhancement of value, with the former representing risk and the latter representing opportunity. Enterprise risk management enables management to effectively deal with uncertainty and the resulting risks and opportunities, thereby improving the organization's ability to create value.

Enterprise risk management is a process that enables management to identify, evaluate and manage risks facing uncertainty, implemented by the board of directors, management and other personnel of an organization. It is applied to strategy formulation and runs through the enterprise. It aims to identify potential issues that may affect the organization, manage risks so that they are within the risk container of the organization, and provide reasonable assurance for the realization of the organization's objectives. Therefore, it is essential for value creation and maintenance.

Establishing enterprise risk management is of great significance to reduce costs, especially in the highly competitive market faced by many companies. Unnecessary procedures and costs can be avoided by focusing on existing operations and their contribution to effective enterprise risk management and integrating risk management into basic business activities. Furthermore, building enterprise risk management within the basic framework of doing business can help management identify new opportunities to capture them for business growth. Well-designed and well-functioning enterprise risk management provides reasonable assurance for the management and the board of directors to realize the organizational objectives.

\section{Overview of Research Status}

ISSN: 0010-8189

(C) CONVERTER 2020

www.converter-magazine.info 
In 1985, the American Institute of Certified Public Accountants, the Accounting Association, the Financial Executive Institute, the Institute of Internal Auditors, and the Institute of Management Accountants jointly established the Treadway Committee, which aims to explore the causes of fraud in financial reporting and find solutions. Two years later, the Committee made many valuable recommendations, based on which its sponsoring agency established a COSO Committee to study internal control issues. In September 1992, the COSO Committee put forward its report Internal Control-Overall Framework (supplemented in 1994), namely the COSO Internal Control-Integrated Framework.

The proposal of COSO Internal Control-Integrated Framework marks a new stage in the development of internal control theory, which is of great significance for enterprises to improve and optimize internal control and enhance risk prevention ability. The COSO Internal Control-Integrated Framework has been widely selected as the standard for constructing and perfecting internal control system because although it is not the only internal control framework, it is the only one recommended by the US Securities and Exchange Commission. In addition, the "Final Rules" in Article 404 of Sarbanes-Oxley Act clearly indicates that COSO Internal Control-Integrated Framework can be used as a standard for evaluating internal control of enterprises. Moreover, companies listed on the New York Stock Exchange are required by the Act to introduce the COSO internal control framework to integrate existing internal controls to meet the requirements of the Act. At the same time, it is also an opportunity to sort out the management process, standardize the management and improve the overall management level of the company. COSO Internal Control-Integrated Framework is ideal, almost superior to that of all companies, and American companies are working hard for it, which will inevitably increase the burden on enterprises, but most companies hope to achieve the purpose of improving management level by understanding and implementing it.

The COSO Committee has been continuously exploring the field of internal control and enterprise risk management, and updated the old enterprise risk management framework in 2017. Kyleen Prewett and Andy Terry (2018) analyzed the new and old versions of the enterprise risk management framework and concluded that although the content of the new version of the enterprise risk management framework does not have disruptive innovation, the new framework focuses on the importance of strategic choice, performance integration and governance culture, making enterprise risk management (including financial risk management) no longer limited to process management, but expanded scope for diversified integration. [1]

Chinese scholars are also actively thinking about how to apply COSO Internal Control-Integrated Framework and enterprise risk management framework to management practice. Zhang Jide and Zheng Li'na (2012) believed that the COSO Internal Control-Integrated Framework is not suitable to be directly applied to domestic companies. Then, they draw lessons from it and put forward a financial risk management framework for group business which includes three levels and five elements. That is, on the premise of clearly formulating the target layer, enterprises need to do a good job in the management layer (core part) and the basic layer (bottom guarantee), and the three layers correspond to specific elements such as management objectives, responsible subjects, procedures and methods, guarantee system and management foundation. [2]

Jia Yulu (2013) proposed the assumption of financial risk control system under old version of COSO risk management framework based on the research results of financial risk status of iron and steel enterprises, and believed that enterprises should optimize the financial risk control process after improving the organizational structure, and ensure the implementation effect of the aforementioned work through the implementation of internal supervision and incentive mechanism. [3]

Since the new version of COSO enterprise risk management framework has just been released recently, domestic scholars are basically in the exploratory stage. Shu Wei et al. (2018) analyzed the new framework and thought that

ISSN: 0010-8189

(c) CONVERTER 2020

www.converter-magazine.info 
Volume 2021, No. 3

government regulators should continue to issue risk management guidance documents in line with national conditions, and enterprises should actively integrate risk culture, improve organizational structure and use IT technology in risk management practice. [4] He Yuhuan (2018) pointed out through the research of software enterprises that the current internal financial control of enterprises has problems such as lack of staff awareness and poor internal execution, and held that the company should actively implement an effective risk management system, improve the internal financial control environment, and increase monitoring efforts. [5]

At present, there are still some gaps between the internal control of Chinese enterprises and the requirements of COSO Internal Control-Integrated Framework, which are mainly reflected in the facts that the overall framework of internal control system, control environment, risk assessment and other concepts have not been widely accepted, the documentation of internal control is not systematic and standardized, and the self-assessment mechanism is lacking. As an old Chinese saying goes, Jade can be polished by stones from other hills. The COSO Internal Control-Integrated Framework has enlightening and referential significance for strengthening the internal control of enterprises.

\section{Presentation of Question}

In this paper, COSO-ERM framework is firstly mainly introduced, and the conventional short-term financial investment risk control process of enterprises is then incorporated into the overall risk management system of enterprises, and finally the top-down short-term financial investment risk management model and the related risk measurement model are explored based on the strategic objectives of enterprises

\subsection{Decoupling of short-term financial investment behavior of enterprises from their strategic objectives}

Short-term financial investments of enterprises are mainly for financial products such as stocks, bonds, funds, derivatives, etc. with a holding period usually not exceeding 1 year. Referring to the corporate governance and risk management model of financial institutions, enterprises generally need to set up special investment departments and risk control departments in the organizational structure (Fig. 1), with the former responsible for short-term financial investment activities and the latter responsible for the overall risk management of enterprises including investment. Generally speaking, the investment department is headed by the investment director and comprises an investment research team and a trading team. The risk control department is headed by the risk control director and comprises a compliance team and a risk control team.

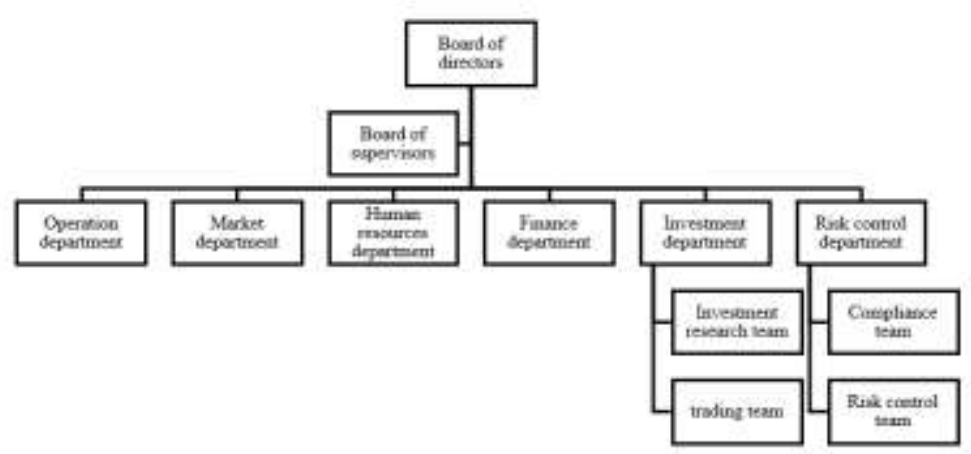

Fig. 1: Organization of company

Specifically, the investment director of the investment department is responsible for formulating and regularly

ISSN: 0010-8189

(C) CONVERTER 2020

www.converter-magazine.info 
Volume 2021, No. 3

adjusting the overall financial investment plan of the company, forming investment strategies, deciding the asset allocation ratio of investment funds, and regularly reviewing and adjusting investment restrictive indicators. The Investment research team conducts securities analysis activities according to the overall investment plan formulated by the investment director, mainly engaged in macroeconomic analysis, industry development analysis, investment value analysis of listed companies and financial derivative instruments analysis, providing research reports and investment plan suggestions, screening and portfolio management of securities targets according to relevant reports and plan suggestions, forming investment strategies and issuing investment instructions to the trading team. At the same time, the investment research team is also responsible for the feedback of the investment plan, providing timely market dynamic information and the implementation results of the investment strategy to the investment director. The trading department is the specific executive department of financial investment operation, responsible for executing the trading instructions of the investment research team, recording and saving the daily investment transactions, maintaining contact with securities dealers and controlling the corresponding trading quota, etc.

The risk control director of the risk control department is responsible for comprehensively controlling all risks in the company's operation and management, including operational risks, process risks, technical risks, financial risks, legal compliance risks, operational risks, moral risks, investment risks, market risks and liquidity risks, so as to ensure that the company's risk control is consistent with business objectives, and mainly assessing investment operation risks, market risks, liquidity risks and operational risks existing in investment research and transaction implementation. The compliance team is responsible for the legal and compliance affairs of the company. It mainly supervises and inspects the legitimacy, compliance and internal control of the investment operation, and reports to the risk control director in a timely manner and plays an important role in the operation, investment operation, protection of shareholders' interests, improvement of the internal control system of the company, detection of errors, prevention of malpractices, and closure of loopholes. The risk control team is responsible for effectively identifying, managing and reporting the potential risks arising from the company's operation, identifying the potential risks of the market and investment targets involved in financial investment activities, formulating effective investment risk control plans, implementing investment risk analysis and control, performing performance attribution analysis on investment portfolios, analyzing the effectiveness of investment operation process, making timely and accurate risk reports and putting forward targeted suggestions, and reporting to the risk control director.

Under the traditional organizational structure, the uncertain risk of investment income has adverse effects on the formulation and implementation of enterprise strategic objectives mainly in the following aspects. First, the investment department fails to formulate the investment report and investment strategy according to the strategic objectives of the enterprise. The investment department usually regards the corporate strategic objectives, especially the expected investment return objectives, as a reference indicator or the lowest indicator, and focuses on the comprehensive consideration indicators of the expected return rate and risks of the investment strategy itself, such as the Sharpe ratio, so that there is a large difference between the expected investment return and the actual investment return, and ensures no corresponding adjustment mechanism is designed when such difference occurs. Second, the investment risk management and control function is relatively weak. In the traditional organizational structure, the functions of the risk control department mainly focus on the risk management of legal compliance risk, investment risk, market risk and liquidity risk, with relatively weak response to process risks, especially the whole process monitoring of investment activities of the investment department. Third, the investment department's pursuit of excess investment income brings uncertainty risk, which mainly occurs when the investment department has achieved the expected investment income target and failed to take corresponding risk control measures in time. As a result, in the process of pursuing excess investment income, investment losses are caused due to changes in the market environment, and the expected investment income target has not been achieved. Therefore, it is necessary to introduce COSO-ERM framework to strengthen the internal control and risk control of short-term financial investment activities of enterprises, whether from the perspective of enterprise strategy implementation or risk management.

ISSN: 0010-8189

(c) CONVERTER 2020

www.converter-magazine.info 


\subsection{Introduction of COSO-ERM framework}

Under the framework of COSO-ERM, enterprise risk management is a process that serves the formulation of strategies, flows continuously within the organization, and is applied at all levels and units throughout the enterprise. It is implemented by personnel at all levels in the organization. The purpose is to identify potential events that will affect the organization once they occur, control the risks within risk containers, strive to achieve one or more different types of but cross-cutting objectives, and provide reasonable assurance to the management and board of directors of an organization. A three-dimensional model is used in COSO-ERM framework (Fig. 2) to describe enterprise risk management system.

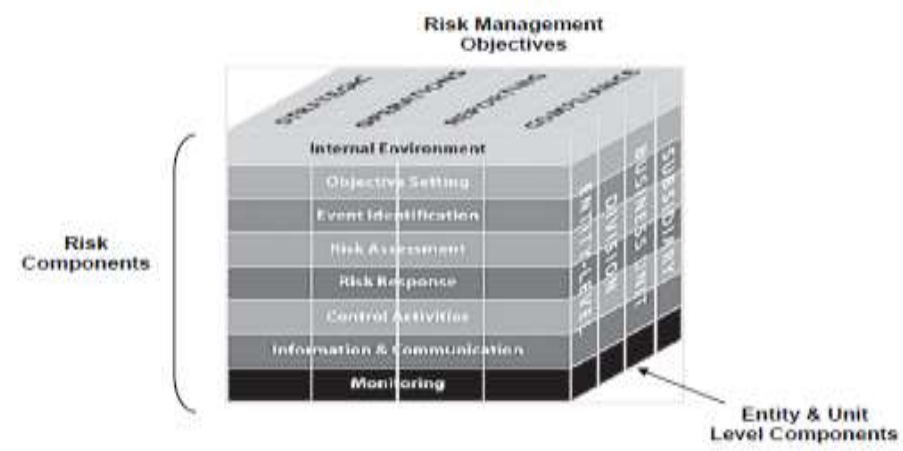

Fig. 2: COSO-ERM framework

Source: Prewett K., Terry A.. COSO's Updated Enterprise Risk Management Framework- A Quest For Depth And Clarity. Journal of Corporate Accounting \& Finance, 2018, 29(3):16-23.

The first dimension (D1) of the COSO-ERM framework is the category of organizational objectives, which is divided into four aspects: strategies (D11), operations (D12), reporting (D13) and compliance (D14), so that attention can be paid to different aspects of enterprise risk management. A specific organizational objective can be classified into one or several categories, which reflects the behavioral tendencies among different subjects in the organization and helps to distinguish what different subjects expect from this objective.

The second dimension (D2) of the COSO-ERM framework is the constituent elements of enterprise risk management, including eight interrelated constituent elements, which are derived from the way the management manages the enterprise and integrated with the management process, namely: internal environment (D21), objective setting (D22), event identification (D23), risk assessment (D24), risk response (D25), control activities (D26), information \& communication (D27) and monitoring (D28). Enterprise risk management is not just a process in which elements influence each other in turn, but a multi-directional and repeated process, in which almost every element can and will influence another element.

The third dimension (D3) of the COSO-ERM framework is the organizational structure, covering the entire structure including entity level (D31), division (D32), business unit (D33), subsidiary (D34), etc. It is closely related to the whole organization and any one of its units.

The relationships among the three dimensions of COSO-ERM are all eight elements of enterprise risk management serve the four objective categories of the enterprise; all levels of the enterprise should adhere to the same four objective categories; each level must carry out risk management from the above 8 aspects. The framework is suitable for the risk management of various types of enterprises or institutions.

COSO-ERM has proposed a relatively complete three-dimensional model of enterprise risk management, which ISSN: 0010-8189

(c) CONVERTER 2020

www.converter-magazine.info 
Volume 2021, No. 3

however still remains in the level of theoretical discussion and practical guidance. Different enterprises have different enterprise risk management practices, and there are still a few Chinese enterprises that truly carry out COSO-ERM risk management according to the actual situation in China.

3.3 Risk management and control process of enterprise short-term financial investment under COSO-ERM framework

COSO-ERM breaks down the company's strategic objectives from top to bottom, and formulates corresponding internal risk management measures starting from the strategic level of the company. Generally speaking, the management (D31) will jointly formulate the annual strategic objectives (D11) at the production and operation planning meeting held at the beginning of the year. For example, the company sets the total expected profit for the year as a growth target of $15 \%$, in which the expected contribution of operating income is $10 \%$, and the expected contribution of investment income is not less than 5\%. After the investment department (D32) confirms the investment income target, it starts to formulate the annual financial investment master plan (D12). The investment research team and the trading team (D33) perform investment analysis according to the overall investment plan, prepare investment reports and make investment strategies, execute transaction instructions, and feed back the investment operation process and the implementation results of the investment strategies to the Investment Director as an investment report (D13). On the other hand, the risk control department (D32) will conduct compliance review and risk assessment (D12) according to the annual overall financial investment plan formulated by the investment department. The compliance team and the risk control team track the whole process of investment research and trading according to the investment report and investment strategy, and prepare a compliance report (D14) and a risk control report (D13), which are fed back to the risk control director.

As far as the risk management and control process of financial investment is concerned, the risk control department must monitor the financial investment activities of the investment department in the whole process (D28). The risk control team should first clarify the internal production and operation environment (D21) on which the company relies to carry out short-term financial investment activities, including the information closely related to it, such as annual strategic objectives, expected investment income targets, annual financial investment overall plan, investment report and investment strategy, as well as the extended information such as the company's production and operation, the company's assets and liabilities, net profit and liquidity. Then, it will set risk control objectives (D22) based on the risk measurement conclusions drawn from the investment report and investment strategy, namely, the process risk control objective after the investment return objectives are achieved, and the process risk control objective after the extreme risk events trigger the investment stop loss objectives. Correspondingly, two sets of risk disposal schemes covering event identification, risk assessment and risk response should be formulated for the two risk management and control objectives, namely, investment profit-taking risk disposal plan and investment loss-stopping risk disposal plan. The former mainly refers to the analysis method (D24) adopted to summarize the investment income after the investment income reaches the established target set by the annual financial investment overall plan (D23), and the follow-up action plan (D25) that the investment department needs to implement. The latter mainly refers to the accounting treatment method (D24) of investment loss after the floating loss of investment triggers the loss-stopping target set in the annual financial investment overall plan (D23), and the loss-stopping action plan (D25) that the investment department needs to implement. On this basis, the risk control department must track (D26) the financial investment activities of the investment department in the whole process, especially the trading behaviors. Generally, a "T+1" reporting and tracking system is established, that is, all financial transaction records occurring in the previous trading day are required to be collated and reported on each trading day, and any abnormal trading behaviors and even irregularities must be communicated with the investment department in time once found (D27).

ISSN: 0010-8189

(c) CONVERTER 2020

www.converter-magazine.info 


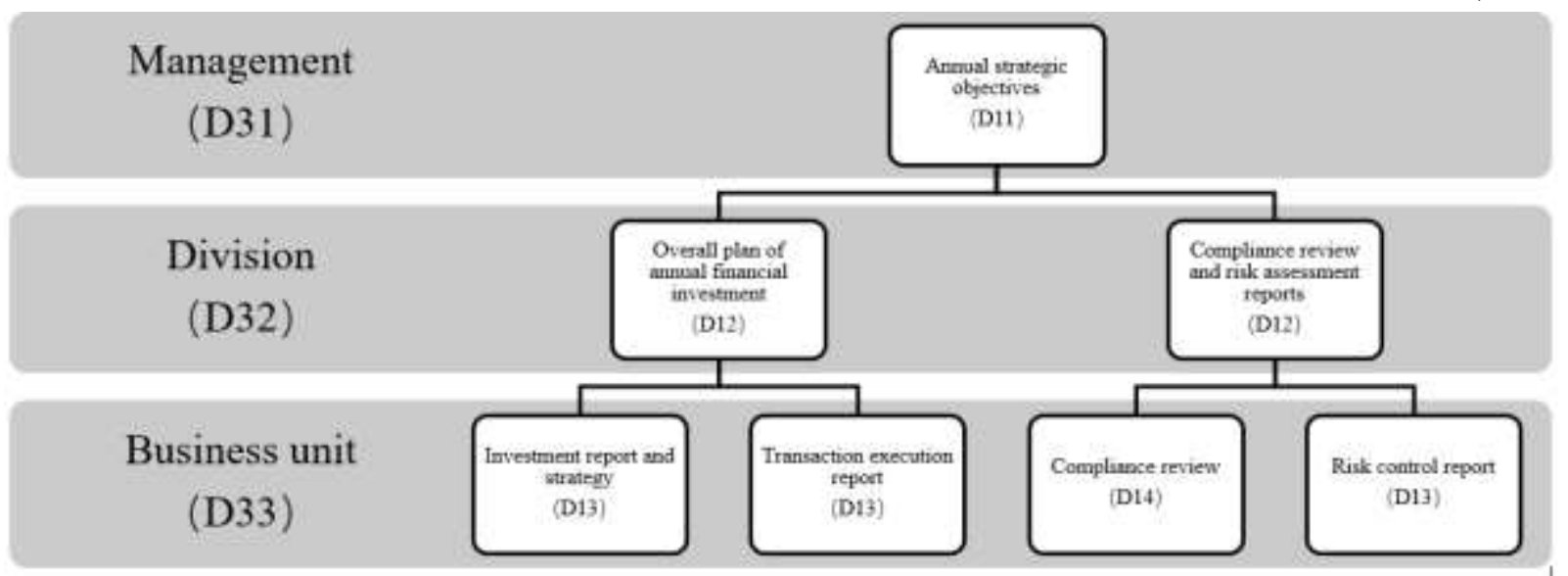

Fig. 3: Risk management under COSO-ERM framework

The main problem now is how to solve the problem of decoupling of the short-term financial investment behavior of enterprises from their strategic objectives after the introduction of the COSO-ERM framework, i.e. how to effectively implement the strategic objectives of enterprises into the financial investment process, so that the expected yield on investment strategies can be effectively aligned with the strategic objectives of enterprises, and effectively strengthen the investment risk control function. For example, as mentioned above, how does the "5\% expected return on investment" investment return target fit into the investment strategy?

\section{Risk assessment and Control of Investment Strategies}

For illustration purposes, the following hypotheses are made:

The Company has set the target of total expected profit for the year as an increase of $15 \%$, of which the contribution of expected investment income is not less than 5\%;

To avoid significant investment losses caused by extreme risk events, the investment loss-stopping line is set at-15\%; The assets are allocated by portfolio management, but the types of investment securities are limited to stocks;

The passive investment duplicates the CSI 300 index completely, i.e. it purchases all the constituent stocks in the target index and determines the buying and selling proportion according to the weight of each constituent stock in the target index. Therefore, the change trend of the CSI 300 index is that of the net value of the investment portfolio. In order to illustrate the problem, it is further assumed that the Company replaces the portfolio allocation by purchasing the CSI 300 index Fund;

Buying and holding, one-time buying with the longest holding period of half a year (120 trading days), and selling immediately when meeting any of the expected investment income targets or investment stop loss targets during the period;

Transaction costs such as handling fees and commissions are ignored.

\subsection{Descriptions of investment strategies}

In this paper, the research object of CSI 300 index is selected from April 8, 2005 (listing date) to December 31, 2019, and the data type is daily closing price, with a total of 3,585 pieces.

ISSN: 0010-8189

(C) CONVERTER 2020

www.converter-magazine.info 
Volume 2021, No. 3

Without considering the market fluctuation trend, the investment department can allocate (buy) all the CSI 300 index funds (the underlying securities) at any time, and sell them all after 120 trading days without considering the profit-taking and loss-stopping targets, and calculate the return rate of this investment. A total of 3,465 pieces of data were obtained in the study area, and the related statistical characteristics are shown in Table 1.

Table 1 Statistical characteristics of return

\begin{tabular}{|c|c|c|c|c|c|c|c|c|}
\hline & count & $\begin{array}{c}\text { mean } \\
(\boldsymbol{\mu})\end{array}$ & $\begin{array}{c}\text { std } \\
(\boldsymbol{\sigma})\end{array}$ & $\mathbf{m i n}$ & $\mathbf{2 5 \%}$ & $\mathbf{5 0 \%}$ & $\mathbf{7 5 \%}$ & $\max$ \\
\hline return & 3465 & 0.0503 & 0.2797 & -0.8944 & -0.1137 & 0.0380 & 0.1653 & 0.9402 \\
\hline
\end{tabular}

Generally speaking, according to the statistical characteristics such as mean value and standard deviation, comprehensive consideration indicators such as Sharpe ratio of investment strategies can be further investigated to judge the feasibility of investment strategies. However, there is no intention to further explore the merits and feasibility of this passive investment strategy in this paper.

\subsection{Risk assessment of investment strategies}

It is impossible to fully reveal the risk characteristics of investment strategies only by means of statistical characteristics such as mean and standard deviation, but it needs to further characterize the risk status of investment strategies by means of risk profile tools. Given the mean and standard deviation of the yield of the investment strategy, assuming that the yield sample of the investment strategy obeys the normal distribution, the Cumulative Distribution Function of the normal distribution yield $N(\mu, \sigma)$ can be obtained.

$$
\mathrm{F}(\mathrm{X})=\frac{1}{\sqrt{2 \pi} \sigma} \int_{-\infty}^{x} \mathrm{e}^{-\frac{(x-\mu)^{2}}{2 \sigma^{2}}} \mathrm{~d} x,-\infty<x<+\infty
$$

Furthermore, the inverse of the cumulative distribution function is obtained, and the Survival Function is obtained.

$$
\Phi(\mathrm{X})=1-\mathrm{F}(\mathrm{X})
$$

Specially, $\Phi(-0.15)=0.7631, \Phi(0.05)=0.5005$. The corresponding survival function curve is shown in Fig. 4 .

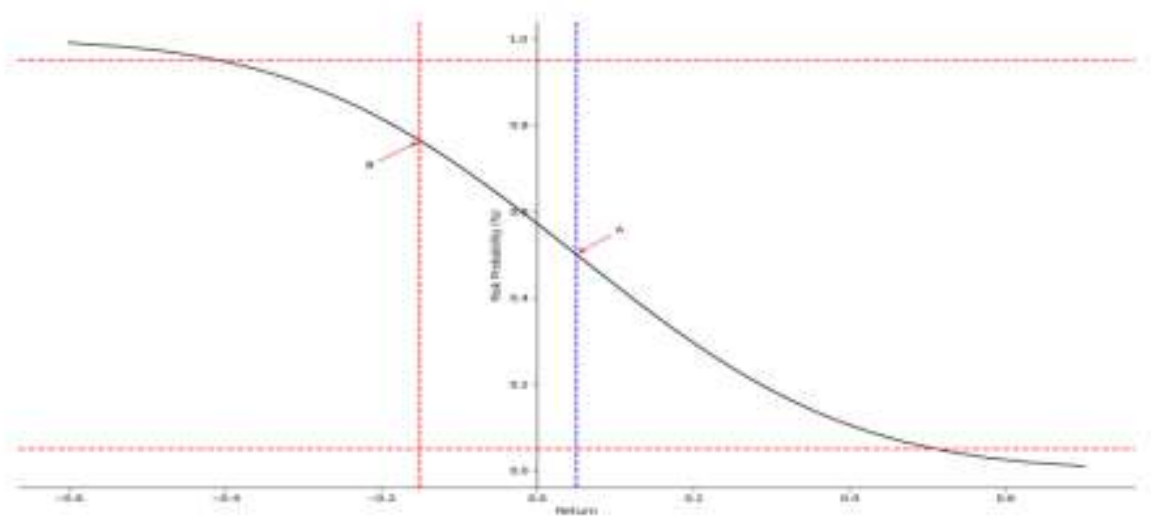

Fig. 4: Survival function curve

Point $\mathrm{A}$ in the figure indicates that the risk probability with the yield of not less than $0.05(5 \%)$ is $0.5005(50.05 \%)$, i.e., $\Phi(0.05)=0.5005$. Under this strategy, the probability of any single investment is only $50.05 \%$ so that the yield is not less than $5 \%$. Then the expected yield of any single investment is $0.05 \times 0.5005=0.0250(2.5 \%)$. In other words, two investments are required in each year to achieve the expected return on investment.

ISSN: 0010-8189

(c) CONVERTER 2020

www.converter-magazine.info 
Similarly, point B in the figure indicates that the risk probability with the yield of not less than $-0.15(-15 \%)$ is $0.7631(76.31 \%)$, i.e., $\Phi(-0.15)=0.7631$. Under this strategy, the probability of any single investment is only $76.31 \%$ so that the yield is not less than $-15 \%$. However, it is worth noting that more attention is paid to the probability of occurrence of extreme risk events such as triggering the loss-stopping mechanism, i.e. the probability that the yield is less than $-15 \%$, i.e. $1-0.7631=0.2369$, which means that the investment strategy still has a high probability $(23.69 \%)$ of triggering the loss-stopping mechanism.

It is easy to see that any point on the survival function reflects the relationship between yield (performance) and probability of return realization (risk probability). It means that the higher the yield, the lower the probability of achieving the yield and the higher the risk of not meeting the target of expected investment return contribution. Therefore, the survival function can be regarded as the risk probability curve to evaluate the risk of investment strategy, i.e. risk image, to achieve a complete description of the risk status of investment strategy as an important basis for investment strategy risk assessment. In fact, this risk image tool can be applied to risk management of other business modules in the enterprise.

In practice, some enterprises use risk curves in risk assessment (risk image) rather than risk probability curves, including those used in COSO-ERM references, as shown in Fig. 5. Risk curve reflects the relationship between risk and performance changing in the same direction, indicating that the higher the performance (yield), the greater the risk, and the main tool to measure the risk is variance (or standard deviation), which is more intuitive and conforms to people's common sense on the relationship between return and risk. However, the deficiency is also obvious. First, the expected value cannot be calculated because the ordinate of the risk curve is variance. Usually, it is desirable to establish a direct relationship between the expected target and the actual result, so that the feasibility of the expected target can be well evaluated in actual work. As mentioned above, the expected yield can be obtained by multiplying the actual yield and the risk probability, and then compared with the expected investment income contribution target set by the strategic target, so as to assess the feasibility of the strategic target, and thus solve the decoupling problem between implementation and target. Second, different types of risks, such as operational risks and process risks, can't be compared directly even if they get their own risk curves because the variances of their respective risks are not in the same dimension. Sometimes even the same type of risk, such as investment risk, cannot be directly compared due to the investment strategies designed for different markets. Third, it is impossible to quantify the possibility of achieving the overall strategic objectives. The risk appetite of enterprises towards this type of risk can be clearly seen in the risk curve. It is feasible as long as the risk corresponding to the expected target (target), i.e., the intersection point of the risk curve and the expected target line in the figure, is lower than the risk appetite. However, it is impossible to know how likely it is to achieve the desired target. In other words, this approach focuses on whether the risk of the intended target is acceptable, regardless of whether the intended target is achieved. Obviously, these two aspects are very important in enterprise risk management.

ISSN: 0010-8189

(c) CONVERTER 2020 


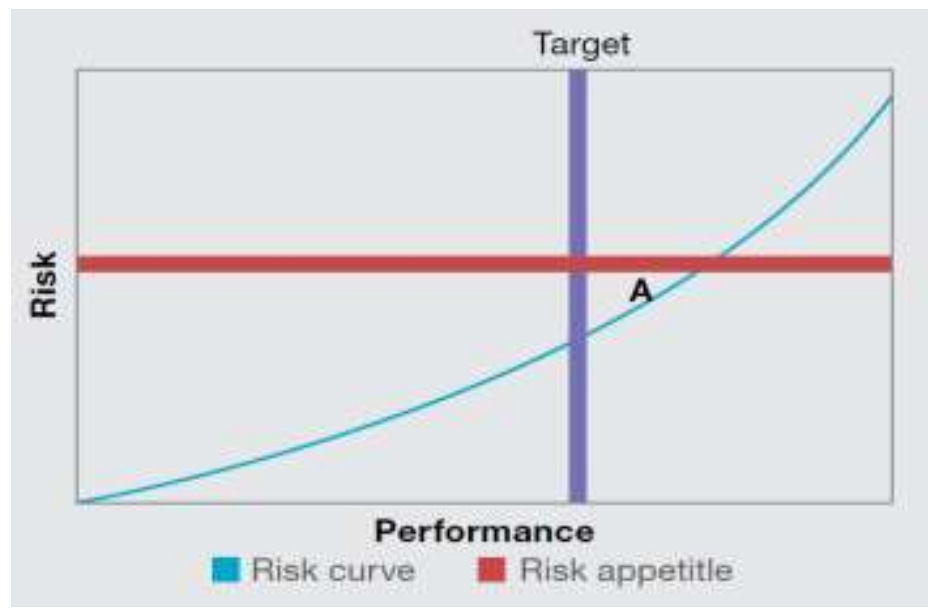

Fig. 5: Risk image

Source: COSO. Enterprise Risk Management Integrating with Strategy and Performance (Appendices). 2017(2). p20.

In fact, it is not new to use risk probability to measure risks. VaR method, which is commonly used in risk management, has been widely used in risk assessment of various projects, with very good results. However, the difference is that when using VaR method to evaluate project risks, it seldom starts from the enterprise strategy and internal control to grasp the overall risk level of enterprises and the possibility of achieving strategic objectives.

To sum up, in this paper, firstly, the risk management and control process of related enterprises after COSO-ERM framework is introduced and the risk assessment and control methods of related investment strategies are introduced emphatically by studying the short-term financial investment business of enterprises. Then, the risk probability method for measuring the risk size and the possibility of achieving the expected goals is introduced. Next, the differences between the risk curve and the risk probability curve are further compared. Finally, it is concluded that the introduction of COSO-ERM framework into enterprise risk management will not only help to grasp the implementation of enterprise strategic objectives through effective internal control, but also help to effectively assess the risks of strategic objectives and the possibility of achieving strategic objectives.

\section{References}

[1] Kyleen Prewett, Andy Terry, "COSO's Updated Enterprise Risk Management Framework-A Quest For Depth And Clarity," Journal of Corporate Accounting \& Finance, vol. 2018, no. 29.

[2] J. D. Zhang, L. N. Zheng, "Discussion on the financial risk management framework of group enterprises," Accounting Research, vol. 12, pp. 50-54+95, 2012.

[3] Y.L. Jia, "Financial risk control of diversified operation of iron and steel enterprises in China," Chang 'an University, 2013.

[4] W. Shu, R Zuo, Y. Chen, J. Wen, "New development of COSO risk management framework and its enlightenment," Journal of Xi 'an University of Finance and Economics, vol. 31, no. 05, pp. 41-47, 2018.

[5] Y. H. He, "The role of COSO model in financial internal control of software enterprises," Accounting Learning, vol. 17, pp. 243-244, 2018.

ISSN: 0010-8189 